\title{
BUSINESS PROCESS RE-ENGINEERING OF A MARITIME CAR TERMINAL: CHANGING FROM INBOUND TO OUTBOUND INTERMODAL NODE IN FINISHED VEHICLE LOGISTICS (FVL)
}

\author{
Bojan Beškovnik \\ Marina Zanne \\ Faculty of Maritime Studies and Transportation, Pot pomorščakov, Slovenia
}

\begin{abstract}
This article presents a broad perspective on a maritime car terminal's role in finished vehicle logistics with an aim to elaborate the process when a terminal changes its role from an inbound intermodal node to an outbound intermodal platform. Through the analysis of the maritime car terminal in Koper that occupies the $9^{\text {th }}$ position among top European ports in handling light vehicles, a comprehensive view of process re-engineering is provided. The research analyses specific inbound and outbound processes and real-time decisions that influence the terminal's productivity and satisfies stakeholders' business expectations. The proposed business process re-engineering (BPR) model for an outbound car terminal highlights the directions of future management decisions to position the terminal as an export oriented intermodal node. The article offers a theoretical and practical contribution to efficient FVL management.
\end{abstract}

Keywords: finished vehicle logistics; automotive industry; maritime car terminal; intermodal node; business process re-engineering

\section{INTRODUCTION}

The automotive industry is very often exposed to cyclical and turbulent fluctuations. A decrease in GDP development or a global financial crisis has a direct impact on the automotive industry. The final product (car) is a consumable of long-term usage. As a consequence, demand which has a strong influence on production and global supply chains, is lower. Of course, the opposite (positive) direction of demand has global impacts on different supply chains as well, because the time gap between market demand and adjusted production applies pressure on supply elements, production and intermodal terminals.

Intermodal (car) terminals are exposed to both situations, when they have to secure increasing buffers for already produced vehicles, that are hardly sold on the market, and when they have to perform agile and fast services for already paid vehicles.

Car terminals are directly dependent on finished vehicle logistics (FVL) and its strategy. Every car production plant uses personalized logistics chains. Based on a plant's position, the chains are established and later constantly optimised. FVL chains should be short, lean, and agile, and provide all the necessary services expected by both the automotive industry and the final consumer. Mendonça and Dias [11] state that within FVL a car terminal must secure different operational services. Besides loading, discharging and storage services the terminal is very often requested to provide vehicle inspection in different manipulation stages, pre-delivery inspections (PDI), maintenance, car customization, damage repair and in some countries also dissembling and assembling operations.

All requested services in FVL are organised in a certain logistics node that can be closer to the production point or the end consumer. Consequently, car terminal for inbound or outbound flow of new cars may be quite distinct from one another. Very often, more services related to car logistics and customisation are provided in inbound flow, where the node (terminal or dealer's depot) is closer to the end consumers. Such a position within the FVL usually requires different buffer strategies that are tailored to groups of customers. On this basis, 
every car terminal develops its market strategy, strategy of building an adequate infrastructure and internal organisation.

Although there are few literature and scientific articles about car terminals and FVL chains, this specific field of intermodal transport is becoming interesting area of research. The position and role of a car terminal within a global FVL has been analysed by Chandra et al., Dias et al., Fischer and Gehring, Mattfeld and Kopfer, Mendonça and Dias, and Torbianelli $[4,6,7,10,11,14]$. They all see FVL as a very complex chain and express the need of proper process management by the car terminal management to follow FVL expectations. The berth subsystem at a maritime car terminal is managed with higher priority, compared to the storage subsystem or inland delivery zone subsystem. Carriers and their vessels are served with priority status. Moon and Woo [12] claim that from the point of view of total costs, they represent the most important part and their shorter stay in the port significantly reduces terminal and port total costs. Van der Horst and de Langen [15] note that hinterland transport also influences port performance, but operational time-windows are predominantly focused on berthing activities.

Moreover, the inbound and outbound flows usually require different processes and different exploitation of infrastructure. Consequently, the management must monitor and adapt internal processes to the changing market and stakeholders' expectations. Paik and Bagci [13] see the re-engineering process as an important method in securing better customer services and port's performance improvements.

The study of the Koper port car terminal highlights strategic and operational changes that the port adopted in changing its role in FVL through the northern Adriatic transport route. The terminal's initial role as an inbound maritime car terminal for the European market changed into a predominantly outbound platform, serving as an export gateway for European car production. On this basis, the management and operational approach for terminal process re-engineering is highlighted and elaborated in a proposed business process re-engineering (BPR) model for an outgoing oriented car terminal.

\section{THEORETICAL ACKNOWLEDGMENTS AND RESEARCH OBJECTS}

\section{THEORETICAL BASIS}

The FVL chain can be organised as a simple service in moving cars or a higher value chain where additional services are performed on the moving object - the car. Lambert et al. [9] expose that a complex logistics process requires a lot of additional knowledge and skills, in order to secure safety and security levels for cargo and logistics providers. Torbianelli [14] highlights the point that FVL can be observed as an aggregate of very complex services, especially when $\mathrm{RO}-\mathrm{RO}$ and deep-sea transport has to be arranged by operators and different stakeholders. Chandra et al. [4] also point out the complexity and role of processes needed to accommodate the vessel, where these operations directly influence the system's hierarchy decisions.
Mattfeld and Kopfer [10] analyse the transhipment operations and also see the berth subsystem as the most important one, where operational processes and the operational timetable of the entire terminal are connected with berth operational time windows. Undoubtedly, the other subsystems for storage and inland delivery zone are important subsystems with different operational and strategic problems. By defining process hierarchy, Böse and Windt [2] see potentials for autonomously executed processes in the two subsystems. From the flow-managing point of view, the inter-relations between berth-storage subsystems and vice-versa are the most important strategic and operational decisions. Namely, the inbound and outbound flows from land transport that are managed by the inland delivery zone are less intensive and the time pressure is lower. According to Dias et al. [6], terminals and ports must be flexible in offering other services such as postponement services on cars. Carmakers pose special expectations for additional services to be provided by workshops as a part of the unique intermodal node.

From the infrastructural point of view, a maritime RO-RO or car terminal is not a complex system [8]. Even though it uses a large area for storage services, the infrastructural elements are not management's main development priorities. The terminal owners or the management are rather focused on manpower and how to fulfil RO-RO and deep-sea carrier's expectations of shorter waiting times for free berths, shorter stays in the system and higher productivity, with fewer damages to discharged or loaded cars. This is acknowledged by Van der Horst and Van der Lugh [16], who analyse management's focus in managing maritime terminals. According to their research, management and owners are primarily focused on manpower utilisation. They are not oriented towards better process coordination between the subsystems and horizontal communication.

Carbone and De Martino [3] claim that higher productivity can be secured only by understanding and converging the interests of all stakeholders. Certainly, RO-RO operators are an important group of stakeholders, but land transport hauliers (rail operators or trucking companies) have significant role in the system's performance and utilisation. Vilkelis and Jakovlev [17] confirm with their study that they very often suffer from empty runs and low utilisation as a consequence of imbalanced import and export of cars. Their failure in managing inbound or outbound flows directly influences the carrier's operational satisfaction on the berth side, especially when cars must be delivered to the port for just in time loading on the vessel. Consequently, RO-RO carriers, carmakers and inland transport operators dedicate much more attention to the outbound terminal's lean and agile processes.

\section{OBJECTIVE TARGET}

The main orientation of this study is to provide an overview of strategic and tactical decisions which car terminal management takes when cargo flows significantly change direction, quantity, value and scope of additional services. 
The research is not focused on multi-agent simulations, discrete-events simulations or simulation algorithms [1, 7], rather on management's decisions to provide BPR, in order to achieve operational optimisation and at the same time planned financial results.

The research provides an overview of processes reengineering at a maritime car terminal that is crucial to following a carmaker's expectations and new trends in FVL. Trends in FVL show a constant increase in buying new cars, rising operational costs and changing environmental regulations [18]. Moreover, EU market trends indicate production increases in EU countries, tailor made production based on customer's demand, postponement of services in car modifications, shifting transport of vehicles from RO-RO transport to containers and an increase in exporting luxury cars from the EU market. All these trends directly and indirectly influence a maritime car terminal's market position and performance.

The car terminal in the port of Koper is used as an observed intermodal node. This maritime car terminal is ranked among the top 10 maritime car terminals in Europe [5]. Moreover, the terminal achieved an average yearly throughput increase of $16,3 \%$ over the last 6 years. The cargo flow drastically changed its direction during this period and on this basis the terminal transformed its logistics role from a primarily inbound car port to an outbound one. Today almost $70 \%$ of the terminal's throughput is connected to the export of European car production. In addition, the increase brought higher amounts of luxury cars that require special handling and additional services prior to loading for the new Asian markets.

The research into the last ten years development period and transformation processes yields answers to the following research hypothesis that help build an adequate BPR model for an outbound oriented maritime car terminal:

- Inbound and outbound flow of cars require different processes and real-time decisions that influence terminal productivity,

- Inbound flow uses a maritime car terminal as a mid- or long-term buffer and technology of delivering cars by road transport means are preferred,

- Outbound flows are more complex and difficult to manage, thus the terminal management shall use the BPR model when changing from an inbound to an outbound intermodal node in FVL.

\section{THE STUDY OF KOPER PORT CAR TERMINAL}

\section{KEY TECHNICAL DATA OF THE PORT AND TERMINAL}

The port of Koper is a relatively young port, as it celebrated 60 years of existence in 2017. Presently the port handles over 22 million tons of different cargo that is managed by twelve different and specialised terminals. The port covers 274 ha of land. Out of this 111 ha are used as open storage areas and 49,2 ha for covered warehouses. The total berth length surpasses 3.280 meters and the port offers 28 berths to accommodate different types of vessels. All six profit centres use the same internal road and rail infrastructure. There is no physical delimitation of each terminal area as a unique system; consequently, terminals use storage areas at different locations in the port and combine berth use according to free berths closer to a storage area.

The car terminal uses 7 berths that are situated in all 3 port basins. Pure car carriers (PCC) or RO-RO ships operators are served at the general cargo berth, the container terminal berth or in the basin 3 - used exclusively for RO-RO or deep-sea car vessels. The total berth length is around $800 \mathrm{~m}$ and it is equipped with four RO-RO ramps. The berth subsystem is therefore very complex, which must very often combine the use of a berth with other terminals. Moreover, internal transport processes between the berth and storage subsystem and vice-versa cross other internal flows of different cargo, such as containers, general cargo etc.

The storage subsystem is also very complex in that it uses approximately $750.000 \mathrm{~m}^{2}$ of open space located in various spaces of the port grounds. The biggest storage areas are in the northern and eastern parts of the port. The terminal also handles a five-floor car garage, with a total capacity of $125.000 \mathrm{~m}^{2}$. The last floor is directly connected with RO-RO berths in the first basin by a dedicated bridge. All together, the terminal can accommodate approximately 50.000 vehicles at once. Out of this, 6.000 cars can be stored in the garage.

The car terminal has been operating for 20 years. The first dedicated terminal area was built in 1996. At the beginning, only import cars were handled. Later, the first outbound cars were accommodated by the port. Last year the port of Koper was ranked in the $9^{\text {th }}$ position among top European ports in handling light vehicles [5]. The terminal is ranked immediately after the biggest maritime car terminals in the Mediterranean Sea: Barcelona and Valencia. With a yearly throughput of 749.006 cars handled in 2016, the port of Koper exceeds that of the port of Bristol which handled 719.000 cars.

\section{TERMINAL THROUGHPUT ANALYSES}

During the last 10 years the car terminal handled over 5,6 million cars. In 2016, the terminal achieved a new milestone by surpassing 700.000 cars handled. The total throughput was 749.006 cars. As shown in Fig. 1 the terminal experienced rapid growth in total throughput in the last 6 years. From 2010, when yearly throughput was at the same level as in 2006, the average yearly increase up to 2016 was $16,3 \%$. The forecasted throughput for 2017 is a further increase of $2 \%$ over the 2016 results.

An in-depth analysis shows that the high growth is primarily driven by outbound flows of new cars produced in central European markets. The outbound flow or the European export of cars through the Koper port represents $67,4 \%$ of the terminal's throughput. The terminal handled 504.228 cars in the outbound direction (see Fig. 2). 


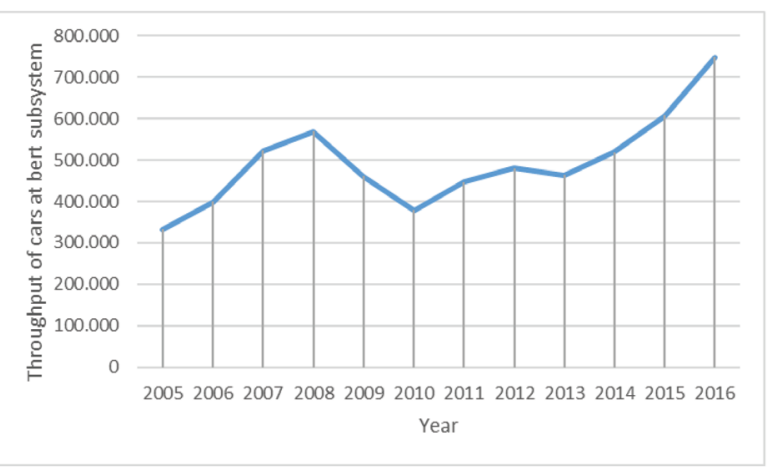

Fig. 1. Number of cars handled at berth in Koper port within2005-2016 period

The main overseas markets are Far East markets and Turkey. The positive trend in outbound flows should continue in the coming years, because the port agreed with the European carmakers to accommodate additional volumes to be shipped to the Far East, where the new market in Japan will be served with a direct deep-sea line.

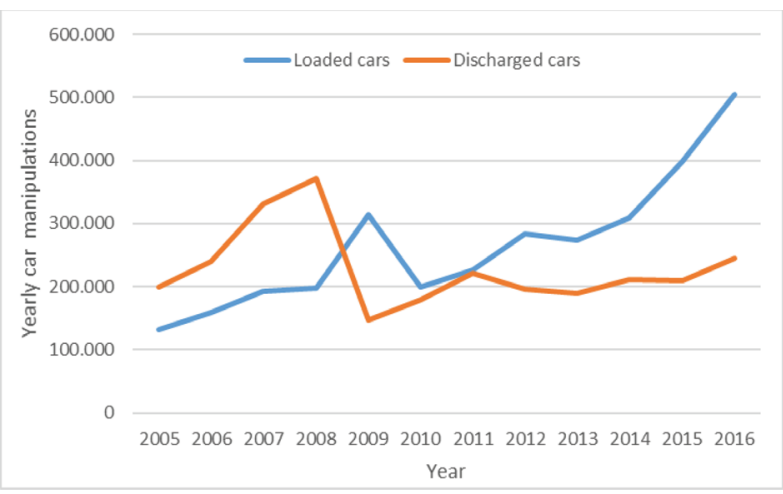

Fig. 2. Number of loaded and discharged cars within 2005-2016 period

The inbound flow represented $32,6 \%$ of the terminal's yearly throughput in 2016, when the terminal handled 244.778 cars for destination markets in central Europe. As shown in Fig. 2 the situation up to 2008 was just the opposite. The terminal was predominantly in function as an inbound intermodal node. The share of discharged cars from the vessels was $65,2 \%$, compared to just $34,8 \%$ loaded onto vessels. The car terminal in Koper was still an important intermodal node of inbound cars with a final destination to Russia. In 2011, the inbound and outbound flows of cars were equal. Later, beginning from 2012, the terminal changed its position to an export intermodal platform for light vehicles, largely.

Further analysis of the terminal's intermodal role shows that inbound cars for hinterland markets in Austria, Hungary, Slovakia, the Czech Republic, Poland and Slovenia are predominantly loaded on trucks. The share of loaded cars on trucks represent an enormous $95 \%$ of total inbound volume. Rail transport is used for just 5\% of inbound volume. Considering that in 2009 the share of cars delivered to the hinterland markets was $7,2 \%$ and in 2013 was just 2,6\%, the terminal remains in the same position, where the rail transport is not the first transport choice for car importers in Europe.
According to the analysed data the situation in outbound is just the opposite. Outbound cars arrive by rail to the terminal at the rate of $68 \%$ of total outbound volume. Regular block trains to the Koper port are used from production plants in Germany, Hungary, Slovakia and Czech Republic. Arrivals by truck thus represent $32 \%$. Considering the inbound and outbound flows in numbers, 232.500 cars are picked up by trucking companies; meanwhile just 161.350 cars are delivered to Koper by trucks. On the other hand, 342.870 cars arrive to Koper by rail and just 12.280 cars leave the terminal on the wagons. There is a huge imbalance in full and empty transport means in arrival or departure from Koper. To some extent, this penalizes intermodal operators, because one-way transport greatly reduces income. As shown in Fig. 3, the inland delivery subsystem handles 393.900 cars that arrive or depart by trucks and 355.106 cars that arrive or leave the port by rail.

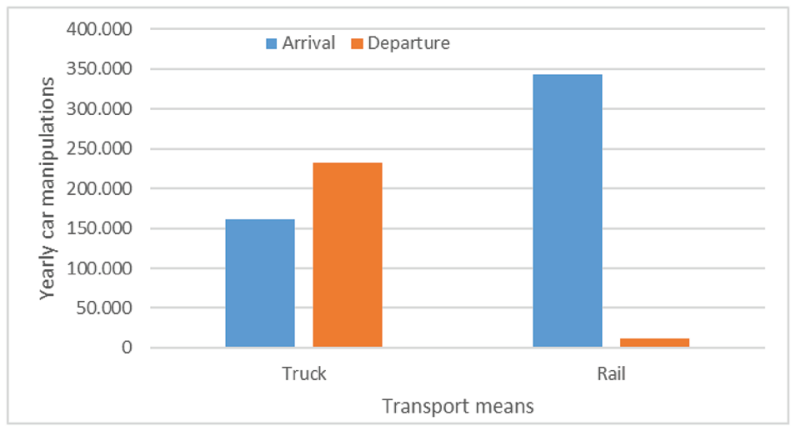

Fig. 3. Number of cars in arrival and departure from the hinterland markets by transport means in 2016

From the terminal's perspective, this imbalance in arrival and departure by rail or truck has several negative impacts on terminal's performance, such as:

- Wagons spend more time waiting for potential outbound volume, because rail operators would like to avoid empty return transport,

- Very often empty trucks must be positioned at Koper, causing higher congestion at the truck terminal, as the arrivals are not always just-in-time to pick up ordered cars,

- A high share of road transport causes a higher degree of random arrivals of a single truck into the system,

- A high volume of cars departing by trucks causes the need for larger loading spaces to be used for preparing cars for each truck (preparing loading lines consisting on average of 6 to 9 cars for each truck).

\section{TERMINAL'S ADAPTATION IN CHANGING ITS ROLE AS INTERMODAL NODE}

The terminal is under strong pressure from the European automotive industry's strategy to increase the European export of new light vehicles to the Asian market. Due to congestion in northern European ports, the port of Koper must find a way to accommodate the increasing number of outbound cars. Consequently, the maritime car terminal is 
constantly adapting its business and operational model from the mostly inbound oriented intermodal node in the past to an outbound one.

This study shows that several changes at different organisational levels must be made to follow market expectations. Firstly, the terminal must handle an increased number of cars that is primarily connected to static capacity of accepting a certain number of cars in the storage subsystem. Secondly, the throughput increase creates pressure on both of the other subsystems because the inland delivery subsystem must accept a higher volume of cars and the berth subsystem must provide enough free berths to accommodate RO-RO and deep-sea vessels.

As an inbound intermodal node, the maritime car terminal at Koper is often used as a storage buffer. Vehicles stay in the system longer (between 20 to 40 days) to be sold while waiting and finally delivered to the end customer. On this basis, the preferred delivery transport mode is road transport. Such a logistic process enables more flexibility and reduces additional costs within FVL, as cars are delivered directly to the dealers or end customers. Of course, this model puts more pressure on the terminal to secure enough storage positions and at the same time to offer longer free storage time.

In the past the terminal was very often requested to provide additional services on cars, such as washing, pre-delivery inspection, car customisation, repairing minor damage caused by transport or by hail; but in recent years, these services have shifted to the dealers' offices. Moreover, in the inbound direction the terminal just unloads the cars from the vessel and positions them at the storage subsystem. This is a simple process, as cars are sorted and shifted later, when they must be prepared for the picking-up by truck or rail or delivered to the workshop (Autoservice Ltd.) within the port area, for additional services on the cars.

On the contrary, as the outbound intermodal node the terminal must prepare a higher volume of cars to be loaded onto certain vessels in advance. This is a more complex process, because the higher volume of cars to be prepared takes a longer time and larger vessel's pre-loading storage area (last point of rest - LPR) must be secured and finally used. The last cars to arrive that are delivered in a last-minute timeframe must be taken into consideration as well. This puts pressure on the inland delivery zone and especially on truck gates. On the other hand, cars spend a shorter time in the system and this reduces the need of car positions in the storage subsystem. Consequently, the terminal faces lower pressure for static storage demand. The use of storage areas for outbound cars is in correlation with the frequency of RO$\mathrm{RO}$ and deep sea lines calling the port. A higher frequency of calls reduces the need for storage space, but as presently Koper has just a biweekly deep-sea line to the Far East, the pressure on the storage area remains at a high level.

Another important element that shapes the FVL chain is connected to the special requirements of certain groups of cars. Luxury cars require a higher level of services and very often a covered storage area. The port of Koper is experiencing an increase in luxury cars movements, therefore the pressure to accommodate cars in the garage and to perform personalised services has increased. The processes involved in parking the cars in a five-floor garage are more complex, require additional transportation time and more work force. In addition, the preloading process of preparing the cars for loading requires additional services such as washing, providing fastening eyes, mounting the eye on both front and rear bumper and later also fastening the car on the vessel just by using the mounted eyes. To follow the export trend of luxury cars, the port of Koper strategically decided to build an additional five-floor garage and to enlarge workshop infrastructure with additional washing lines by 2018 or 2019 . With this, the port will secure additional 5.000 positions for cars.

This study also highlights adaptations in rail infrastructure. Namely, the changing of the port's role from inbound intermodal node to outbound one increased the use of rail transportation. Currently, over 350.000 cars are conveyed by rail wagons; while in 2010 less than one third of this volume was handled. Therefore, the terminal and the port made the important strategic decision to invest in new rail tracks and new rail ramps. The operational adaptation was also needed as the terminal is responsible for unloading cars from the wagon, while truckers unload cars from the trucks by themselves. The terminal also took the operational decision to prolong the working time in the inland delivery zone subsystem and extend the working week to the weekend as well.

\section{DEVELOPING MODEL TO IMPROVE SUBSYSTEMS' ADAPTATION AND EFFICIENCY}

Based on a study of the port of Koper car terminal's development over the last 10 years, a model of business process reengineering (BPR) to secure a reasonable adaptation of processes and infrastructure utilisation, has been worked out. The model highlights certain critical nodes in the terminal's process workflow that have an important influence on lean processes. The outbound and inbound workflows are different from point of view of various aspects. The outbound workflow consists of the following important processes that have different impacts on management's strategic and operational decisions:

- Very often cars arrive into the system by truck and rail until the last day, to be loaded onto the eventually berthed vessel, requiring time-sensitive services,

- Delivery of cars to the workshop can be carried out in different time-steps (directly from the truck gates or rail tracks or later from the storage subsystem or even from the LPR area for last minute services - see Fig. 4),

- Internal shunting of serviced cars from the workshop can be performed in different time periods (to storage yard area, to LPR positions or even directly to berth or vessel),

- The pre-loading process includes a higher number of cars, requires more infrastructure (large storage area for LPR closer to the preselected berth) and labour force, 
- Loading on vessel requires more time and more labour compared to the opposite process of discharging the vessel, causing a longer stay in the system and higher berth occupancy (time-sensitive process).

Other elements, such as the commercial ones, have strong impacts on securing efficient outbound operations that are not present in inbound processes. Storage of cars and pre-loading processes are more complex when different groups of cars are handled (luxury cars, light goods vehicles, large goods vehicles, etc.) and when different services are necessary.

Moreover, before being loaded onto the vessel, cars must be grouped per each port of discharge (POD), in order to load them adequately on the vessel. Being the last outbound terminal on a certain $\mathrm{RO}-\mathrm{RO}$ line, it undergoes commercial pressure to load the maximum possible number of cars, sometimes even more than planned. Thus, the terminal is very often called to accommodate and deliver cars with emergency status (status assigned due to available free space on the vessel or due to the agreed business).

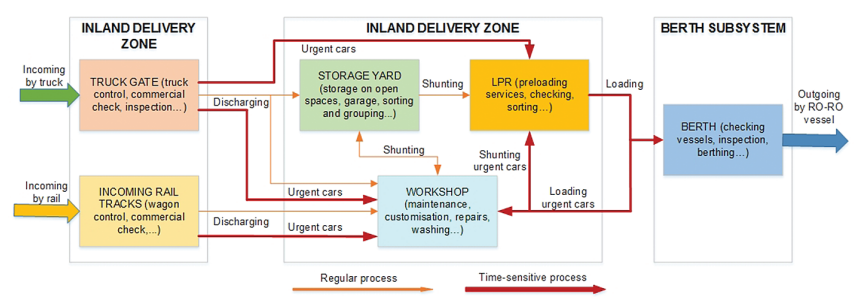

Fig. 4. Workflow of main processes on outbound oriented maritime car terminal

The proposed BPR model for a maritime car terminal, when it is changing from an inbound intermodal node to outbound one, consists of five elements that are managed on different levels (see Fig. 5). Compared to the inbound processes, the described elements pose different focus on their processes due to prioritisation of vessel's accommodation and loading plan. Fig. 5 shows main processes that should be considered in managing outgoing flows.

The inland delivery zone, consisting of truck gates and rail tracks, must secure the following processes:

- Planning working timetables to service cars destined for each vessel,

- Monitoring arrivals of cars by truck or rail with an emergency status,

- Coordinating activities with workshops, storage subsystems, LPR areas and berth subsystems in real-time,

- Prioritising acceptance and control services for cars with an emergency status.

The second element that requires the re-engineering of processes is the workshop. The workshop must secure additional storage space for emergency cars, follow the timetable of berths for servicing cars in concordance with the temporal factors of vessels, prioritise services for cars with emergency status, coordinate activities for lean internal shifting of cars to or from LPR areas, and follow customers' demands for additional services for outgoing cars.
The storage subsystem with an LPR area forms the third and the fourth element. The storage subsystem must accommodate all outgoing cars according to the RO-RO lines' frequency. Higher frequency decreases the need for static storage space, but places greater pressure on LPR areas, the inland delivery zone processes and the workshops. In such cases, more cars with emergency status are anticipated. The processes in an LPR area must be performed more frequently, requiring more work force, but at the same time using less space. In connection to the different groups of cars to be handled through the terminal, the storage subsystem must provide storage in a covered area (garage or hail protected area) and a dedicated storage area as close as possible to the planned berth.

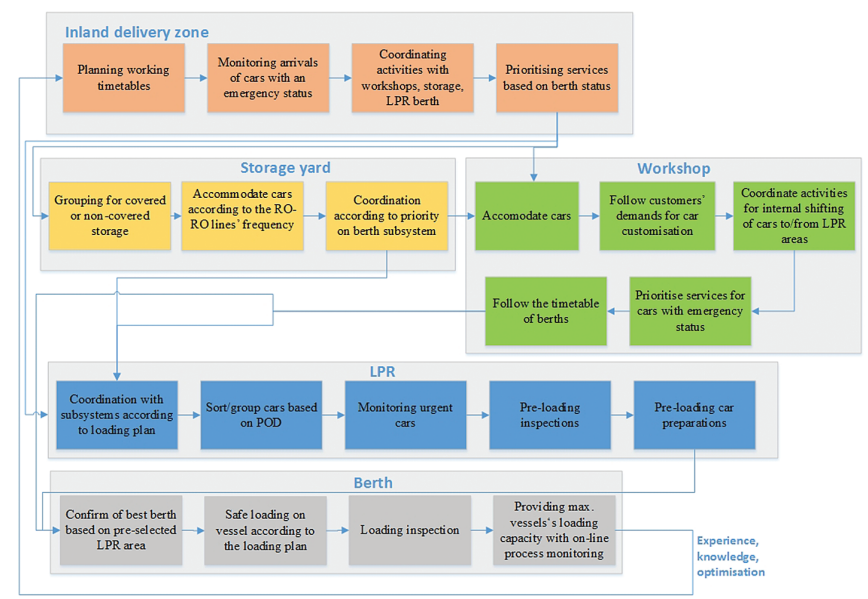

Fig. 5. The BPR model to secure lean outgoing processes at a maritime car terminal with berth prioritisation processes

The fifth element is the crucial element in the process of a maritime car terminal. The berth, with loading processes, determines the system's efficiency. The longer the vessel is in the system the more the pressure is put on other elements, as it results in higher berth occupancy and consequently higher congestion of the entire system. The processes at the berth, when an outgoing vessel has to be served, must provide clear communication with the carrier about free space and loading plans, loading services to secure the utilisation of the maximum vessel capacity and efficiency of loading.

The BPR model elucidates the main bottlenecks a maritime car terminal meets when it must set-up lean outbound processes that follow the commercial interests of stakeholders in FVL. The processes are different from inbound ones; thus, the management must establish a creative environment to introduce BPR as fast as possible. Partial implementation of the processes causes inefficiency and stakeholder dissatisfaction.

\section{CONCLUSIONS}

The study provides a concise view of process managing at a maritime car terminal. Through the research into the first hypothesis that inbound and outbound flow of cars require different processes and real-time decisions, the key elements in process management of inbound and outbound flows are 
highlighted. Based on the study of the port of Koper, the car terminal organisation of the outbound flow of light vehicles is a more complex process, with higher pressure from the perspective of time.

The second research hypothesis that inbound flow of cars uses a maritime car terminal as a mid- or long-term buffer and that the technology of delivering cars by road transport means are preferred, is confirmed. The inbound flow of cars in arrival by vessel for hinterland EU markets is primarily served by road transport. Rail transport represents just 5\% of total throughput. On the other hand, rail transport is used for $68 \%$ of incoming cars for overseas markets. Such imbalance puts operational and commercial pressure on all stakeholders. The transport companies very often use the port's infrastructure as a time buffer in order to optimize inland transport routes.

The research also confirms that outbound flows of cars are more complex and difficult to manage, thus the terminal's management is forced to apply a BPR model when changing from an inbound to an outbound intermodal node. On this basis, a BPR model for primarily outgoing car terminal is designed. The BPR model can be used in all major car terminals, regardless of infrastructure and terminal layout in use. The presented model can be used in a process set-up basis in ports that are establishing car terminals in south Eastern Europe, like the port of Bar, which might become a regular outbound platform for car production in Serbia.

\section{REFERENCES}

1. Aras N., Aksen D., Tekin M. T.: Selective multi-depot vehicle routing problem with pricing, Transportation Research Part C: Emerging Technologies, Vol. 19, No. 5, 2011, pp. 866-884.

2. Böse, F., Windt, K.: Autonomously Controlled Storage Allocation on an Automobile Terminal. In: M. Hülsmann and $\mathrm{K}$. Windt, eds. Understanding autonomous cooperation and control in logistics, Berlin: Springer-Verlag, pp. 351-363, 2007.

3. Carbone, V., De Martino, M.: The changing role of ports in supply-chain management: an empirical analysis, Maritime Policy and Management, Vol. 30, No. 4, 2003, pp. 305-320.

4. Chandra, S., Ghosh, D., Srivastava, S.K.: Outbound logistics management practices in the automotive industry: an emerging economy perspective, Decision, Vol. 43, No. 2, 2016, pp. 145-165.

5. Coia, A.: European ports: Sailing into a tide of protectionism?, Finished vehicle logistics, 3-6, 2017, pp. 40-53.

6. Dias, J.C.Q., Calado, J.M.F., Mendonça, M.C.: The role of European «ro-ro» port terminals in the automotive supply chain management, Journal of Transport Geography, Vol. 18, No. 1, 2010, pp. 116-124.
7. Fischer, T., Gehring, H.: Planning of vehicle transhipment in a seaport automobile terminal using a multi-agent system, European Journal of Operational Research, No. 166, 2005, pp. 726-740.

8. Keceli, Y., Aksoy, S., Aydogdu, Y.V.: A simulation model for decision support in Ro-Ro terminal operations, Int. J. Logistics Systems and Management, Vol. 15, No. 4, 2013, pp. 338-358.

9. Lambert, D., Stock, J.R., Ellram, L.M.: Fundamentals of Logistics Management, International ed. McGraw Hill, Chapter 7, pp. 233-237, 1993.

10. Mattfeld, D.C., Kopfer, H.: Terminal operations management in vehicle transhipment, Transportation Research Part A, No. 37, 2003, pp. 435-452.

11. Mendonça, M.C., Dias, J.C.Q.: Postponement in the logistical systems of new automobiles marketed in Portugal: the Brands and quality, Total Quality Management \& Business Excellence, Vol. 18, No. 6, 2007, pp. 691-696.

12. Moon, D. S.-H., Woo, J. K.: The impact of port operations on efficient ship operation from both economic and environmental perspectives, Maritime Policy \& management, Vol. 41, No. 5, 2014, pp. 444-461.

13. Paik, S.-K., Bagchi, P.K.: Process Reengineering in Port Operations: A Case Study, The International Journal of Logistics Management, Vol. 11 Issue: 2, 2000, pp. 59-72.

14. Torbianelli V. A.: When the road controls the sea: a case study of ro-ro transport in the Mediterranean, Maritime Policy Management, Vol. 27, No. 4, 2000, pp. 375-389.

15. Van der Horst, M.R., de Langen, P.W.: Coordination in hinterland transport chains: a major challenge for the seaport community, Journal of Maritime Economics \& Logistics, Vol. 10, 2008, pp. 108-129.

16. Van der Horst, M.R., Van der Lugt, L. M.: Coordination mechanisms in improving hinterland accessibility: empirical analysis in the port of Rotterdam, Maritime Policy \& Management, Vol. 38, No. 4, 2012, pp. 415-435.

17. Vilkelis, A., Jakovlev, S.: Outbound supply chain collaboration modelling based on the automotive industry, Transport, Vol. 29, No. 2, 2014, pp. 223-230.

18. Williams, A.: Moving with market currents, Finished vehicle logistics, 10-12, 2017, pp. 40-46. 


\section{CONTACT WITH THE AUTHOR}

Bojan Beškovnik

e-mail: bojan.beskovnik@fpp.uni-lj.si

Faculty of Maritime Studies and Transportation

Pot pomorščakov 4

6320 Portorož

SLOVENIA

\section{Marina Zanne}

e-mail:marina.zanne@fpp.uni-lj.si

Faculty of Maritime Studies and Transportation Pot pomorščakov 4

6320 Portorož

SLOVENIA 